\title{
Hubungan Motivasi, Pelatihan, Lingkungan Kerja, Reward Dan Punishment, Beban Kerja, Serta Kompensasi Dengan Kinerja DPJP Dalam Melaksanakan Clinical Document Improvement
}

\author{
Niken Agustinah ${ }^{1}$, Farid Agushybana ${ }^{2}$, Chriswardani Suryawati ${ }^{3}$ \\ Magister Kesehatan Masyarakat Administrasi Rumah Sakit Universitas Diponegoro, ${ }^{1,23}$ \\ agustinahniken@gmail.com ${ }^{1}$
}

\begin{abstract}
Diajukan 28 Januari 2019 Diperbaiki 24 Februari 2020 Diterima 25 Februari 2020
ABSTRAK

Latar Belakang: Rumah sakit seharusnya menyusun strategi clinical document improvement. Pedoman berbasis bukti dalam berkas rekam medis sangat penting untuk memastikan proses clinical document improvement sehingga menjadi jelas, komplit, akurat, dan tidak ambigu.

Tujuan: Menganalisis faktor yang berhubungan dengan kinerja DPJP dalam melaksanakan clinical document improvement. Jenis penelitian adalah penelitian survei dengan pendekatan cross sectional. Metode: Mixed method dengan strategi eksplanatory sequential (kuantitatif dilanjutkan kualitatif menggunakan indepth interview). Populasi penelitian ini semua DPJP (18 orang) dan 100 berkas rekam medis. Pengumpulan data dengan check-list penilaian dokumen dan kuisioner yang diisi DPJP. Analisis data menggunakan uji fisher exact test.

Hasil: Kinerja responden kategori baik dan kurang baik masing-masing sejumlah 9 orang $(50 \%)$.

(72,72\%), berpendapat tidak ada pelatihan 16 orang $(88,89 \%)$, berpendapat lingkungan kerja baik 12 orang $(66,67 \%)$, berpendapat tidak ada reward dan punishment 10 orang $(55,6 \%)$, merasa beban kerja tidak berlebih 10 orang $(55,56 \%)$, berpendapat kompensasi baik sejumlah 10 orang (55,6\%). Hasil korelasi menunjukkan tidak ada yang berhubungan ( $p$ value $>0,05)$. Indepth interview dengan lima responden menunjukkan secara umum motivasi kerja, lingkungan kerja, dan beban kerja masih baik, namun kompensasi dianggap kurang baik dan belum ada pelatihan yang diselenggarakan di RSUD $X$ Jawa Tengah serta belum ada kebijakan khusus yang mengatur sistem reward dan punishment.

Kesimpulan: Motivasi, pelatihan, lingkungan, reward dan punishment, beban kerja serta kompensasi yang baik tidak selamanya berkinerja baik dalam melaksanakan clinical document improvement.
\end{abstract} Responden memilliki motivasi baik 13 orang

Kata Kunci: motivasi; pelatihan; lingkungan kerja; reward dan punishment; beban kerja; kompensasi; kinerja DPJP; clinical document improvement

ABSTRACT

Background: Hospital must develop a strategy clinical document improvement. Evidence-based guidelines in the medical record is very important to ensure the improvement of clinical document so that it becomes clear, complete, accurate and unambiguous.

Objective: Analyze factors associated with doctors performance in implementing the clinical document improvement. Research of type is a cross sectional survey. Method: Mixed methods with sequential explanatory strategy (quantititave followed by qualititative indepth interview). Population is total sampling(18 doctors) and 100 medical record. The collection of data with document assessment check-lists and questionnaires filled out by respondents. Data analysis used Fisher Exact test.

Results: The results showed the performance of the respondents category good and less good to have the same amount that 9 (50\%). Respondents have good motivation $13(72.72 \%)$, who believes there is not training 16 people (88.89\%), who believes a good environment 12 $(66.67 \%)$, which have not opinion of reward and punishment 10 (55.6\%), who feel the workload is not excessive 10 people (55.56\%), who believes compensation is good 10 people $(55.6 \%)$. Correlation result show nothing related ( $p$ value $>0.05$ ). Indepth interview with 5 respondent showed that motivation, work environment, and workload still good, but compensation is not good, there is no training and reward punishment system.

Conclusion: Although the motivation, training, environment, reward and punishment, workload and compensation well, not always perform well.

Keywords: motivation; training; working environment; reward and punishment; workload; compensation; performance doctors; clinical document improvement 


\section{PENDAHULUAN}

Clinical document improvement merupakan hal yang penting bagi pelayanan kesehatan terutama rumah sakit karena berguna untuk mengonfirmasi perawatan kesehatan, patient safety, mengurangi wasting proses koding klaim, dan penagihan biaya asuransi. Dokumen klinik yang tidak berstandar clinical document improvement akan memengaruhi koding dan klaim asuransi yang dibuat koder klinik. Dokter merupakan pemimpin bagi setiap pelayanan pasien, meskipun memeriksa pasien, tetapi tidak menulis hal -hal yang ditemukan dari setiap pemeriksaan yang dilakukan mengakibatkan dokumen klinis menjadi tidak berkualitas. Pedoman berbasis bukti dalam berkas rekam medis sangat penting untuk memastikan proses clinical document improvement dalam mengevaluasi dan mencari hal-hal yang spesifik atau ambigu, yang dilakukan saat pasien masih di rumah sakit agar memungkinkan proses klarifikasi lebih mudah (Reid, 2016).

Clinical document improvement adalah dokumen yang mampu mendeskripsikan secara lengkap assessment pasien, menjelaskan alasan dilakukan pemeriksaan penunjang dan menjelaskan hasil tes yang lengkap dan akurat. Selain itu, linical document improvement bisa mendukung semua diagnosis dan prosedur tindakan yang dilakukan termasuk perubahan dalam membuat diagnosis, membuat rencana perawatan yang lengkap, komprehensif, dan konsisten di antara semua catatan dokter mulai dari awal pasien masuk sampai keluar rumah sakit, catatan kemajuan pasien yang lengkap, tidak ada gap pada perkembangan penyakit, tingkat keparahan, dan manifestasi penyakit atau hubungan penyebab yang hilang/tidak terdeteksi misalnya penyakit jantung akibat ginjal hipertensi, sepsis karena bakteri Echeria coli, infeksi saluran kencing dan lainnya, komplikasi pasca operasi tertulis dengan jelas, kejelasan perkembangan kemajuan diagnosis terkini, hasil pemeriksaan penunjang yang dikonfirmasi dikoreksi oleh dokter (Jamal and
Grant, 2014).

Tabel 1. Perbedaan dokumen klinis pada umumnya dan dokumen klinis setelah diperbaiki (Dietz et al., 2013)

\begin{tabular}{ll}
\multicolumn{1}{c}{ CDI } & \multicolumn{1}{c}{$\begin{array}{c}\text { Dokumen } \\
\text { sesudah CDI }\end{array}$} \\
\hline Abdominal & Abdominal \\
hysterectomy & hystectomy \\
Umur 72 tahun & Umur 72 tahun \\
Berat badan $45 \mathrm{~kg}$ & Berat badan $45 \mathrm{~kg}$ \\
Anoreksia & Anoreksia \\
& Indeksmasa \\
& tubuh $<19$ \\
MS-DRG 743 & MS-DRG 743 \\
& Uterine \& \\
& Adnexa Proc for \\
& Non Malignancy \\
& w/ CC/MCC \\
& GMLOS 3.2 \\
& Rp. 70.000.000 \\
\hline
\end{tabular}

Clinical document improvement merupakan suatu cara mencari hal- hal yang ambigu atau tidak jelas dari dokumen klinis sehingga menjadi lebih berkualitas dan mengurangi pending klaim. Salah satu penyebab pending klaim adalah ketidaksesuaian medis dengan Badan Penyelenggara Jaminan Sosial (BPJS), karena dokumen klinis yang tidak berkualitas. Sehingga BPJS tidak akan atau menunda pembayaran klaim tersebut. Apabila pending klaim dapat diselesaikan sesuai prosedur yang berlaku maka harapan rumah sakit klaim dibayar tepat waktu. Di RSUD X Jawa Tengah persentase pasien BPJS rawat inap menduduki peringkat utama dengan jumlah rata-rata sebanyak 988 pasien perbulan (76\%). Dari studi pendahuluan didapatkan bahwa terdapat kecenderungan kenaikan data pending klaim BPJS bulan Januari sampai Desember 2018, dari 60 (6,08\%) menjadi 190 (19,28\%). Permasalahan pending klaim sebagian besar disebabkan karena dokumen klinis DPJP sering tidak sesuai standar clinical document improvement (51\%).

Dari permasalahan tersebut, peneliti menduga terdapat faktor-faktor yang berhubungan dengan kinerja Dokter Penanggung Jawab Pelayanan (DPJP) dalam melaksanakan clinical document improvement di 
berkas rekam medis rawat inap RSUD X Jawa Tengah. Review berkas rekam medis merupakan gold standard sumber data, tetapi dengan syarat berkas rekam medis yang ada harus memiliki data yang akurat dan lengkap "''(Setyorini, 2018). Kinerja DPJP diduga dapat dipengaruhi oleh motivasi kerja, karena apabila pendapatannya menurun maka kinerjanya menurun. Ada tidaknya pelatihan clinical document improvement juga akan memengaruhi kinerja DPJP karena akan meningkatkan ketajaman dalam menilai tingkat keparahan penyakit, penurunan risiko kematian, ketepatan diagnosis sehingga kinerja dokter menjadi baik(Reyes et al., 2017).

Lingkungan kerja yang nyaman merupakan faktor pendukung terciptanya kepuasan kerja, menambah semangat kerja, mengurangi rasa jenuh dan lelah serta meningkatkan kenyamanan bagi dokter dalam menjalankan pekerjaannya (Meutuah and Ishak, 2015). Adanya reward dan punishment akan memengaruhi bagaimana dokter bekerja sehingga dapat memengaruhi kinerjanya (Setiadi et al., 2019). Beban kerja yang berlebihan dapat memengaruhi kinerja dokter. Beberapa faktor yang diduga menjadi penyebab peningkatan beban kerja dokter antara lain jumlah pasien yang meningkat, persebaran dokter tidak merata, kompleksitas penyakit pasien serta makin banyak proyek penelitian. Kurangnya penghargaan terhadap profesi dokter diduga sebagai pemicu pengaturan jumlah kerja dokter yang berlebihan (Baharuddin et al., 2017). Penerimaan jasa medis (kompensasi) juga akan memengaruhi kinerja DPJP, namun penilaian pemberian jasa medis dinilai subjektif, artinya tidak ada manusia yang sangat puas dalam hal pendapatan, karena kebutuhan hidup tiap individu berbeda tergantung dari pola hidup, jumlah tanggungan dalam keluarga dan target pribadi di masa depan(Syahidin, 2018).

Berdasarkan latar belakang tersebut peneliti ingin mengetahui apakah motivasi, pelatihan, lingkungan kerja, reward dan punishment, kepuasan kerja, serta kompensasi berhubungan dengan kinerja DPJP dalam melaksanakan clinical document improvement di RSUD X Jawa Tengah.

\section{METODE}

Penelitian ini merupakan penelitian mixed methods, dengan metode eksplanatoris sequential dan desain cross sectional. Populasi penelitian adalah 18 DPJP di RSUD X Jawa Tengah yang mempunyai pasien rawat inap bulan Januari sampai Desember 2018. Jumlah sampel diambil menggunakan total sampling yaitu 18 orang karena jumlah populasi $<30$. Untuk menilai kinerja DPJP dalam melaksanakan clinical document improvement, digunakan berkas rekam medis rawat inap BPJS bulan Januari sampai Desember 2018 sebanyak 15.367 dan ditarik sampel sejumlah 100 berkas rekam medis berdasarkan rumus slovin, diambil dengan teknik probalility proportionate simple random sampling. Variabel bebas dalam penelitian ini adalah motivasi, menggunakan 6 indikator (keinginan memperoleh kompensasi yang memadai, kondisi kerja, supervisi yang baik, bertanggung jawab, peraturan yang fleksibel, manajemen memahami pekerjaan karyawan, manajemen berlaku adil, faktor biologis, intelektual dan emosional yang memengaruhi, pengakuan penghargaan dari manajemen, teman sejawat, dan PPA (Profesional Pemberi Asuhan) lain).

Variabel pelatihan diukur menggunakan pertanyaan ada atau tidaknya inhouse training tentang clinical document improvement. Variabel lingkungan kerja diukur menggunakan empat indikator yaitu tata letak ruang kerja bangsal rawat inap tidak menyulitkan dalam bekerja, berkas rekam medis belum dalam bentuk electronic medical record, hubungan baik antara manajemen dan DPJP dan sesama pemberi asuhan klinik, tempat yang nyaman untuk menulis dokumen klinik. Variabel reward dan punishment diukur menggunakan pertanyaan ada tidaknya tentang reward dan punishment yang diterapkan bila DPJP melaksanakan clinical document improvement terkait pending klaim. 
Variabel beban kerja diukur menggunakan sepuluh indikator yaitu waktu dan tenaga yang terkuras sebagai DPJP, kelelahan akibat beban kerja sebagai DPJP, jumlah pasen menjadi beban kerja, kompleksitas penyakit menjadi beban kerja dan memengaruhi kinerja, menjawab konsulan 1x 24 menjadi beban kerja, praktik di beberapa tempat menjadi beban kerja, tingkat kesulitan sebagai DPJP menjadi beban kerja, lingkungan dan desain rumah sakit yang bercampur semua SMF akan menjadi beban kerja, kondisi kesehatan yang tidak baik memengaruhi beban kerja.

Variabel kompensasi diukur menggunakan tujuh indikator yakni besarnya jasa pelayanan memengaruhi kinerja, jasa pelayanan sesuai dengan beban kerja, rasa keadilan dalam menerima jasa pelayanan, transparansi pembagian jasa pelayanan, ketepatan waktu pembagian jasa pelayanan, kesesuaian jasa pelayanan dengan harapan, kepuasan akan kompensasi yang sebanding dengan kebutuhan hidup. Variabel terikatnya adalah kinerja DPJP dalam melaksanakan clinical document improvement yang dilihat dari dokumen klinis dokter apakah sesuai dengan standart clinical document improvement.

Uji normalitas terhadap variabel motivasi kerja, lingkungan kerja dan kompensasi menunjukkan data berdistribusi normal sehingga penyajian data menggunakan mean untuk memberikan kategori pada jawaban yang diperoleh. Variabel beban kerja menunjukkan data berdistribusi tidak normal sehingga penyajian data menggunakan median untuk memberikan kategori pada jawaban yang diperoleh. Uji validitas kuesioner dengan cara menyebarkan kuisioner untuk diiisi DPJP RSUD Y dengan kriteria inklusi dan eksklusi yang sama dengan RSUD $X$ Jawa Tengah. Analisis data menggunakan uji fisher exact test. Sebelum penelitian dilakukan, penelitian ini sudah mendapatkan Ethical Aproval no 388/ EA/KEPK-FKM/2019.

\section{HASIL DAN PEMBAHASAN}

Karakteristik responden yang dilihat dalam penelitian ini meliputi jenis kelamin, usia, lama kerja, jumlah tempat praktik, gaji dan jasa pelayanan yang diterima.

Tabel 2. Karakteristik responden

\begin{tabular}{|c|c|c|}
\hline Karakteristik & $f$ & $\%$ \\
\hline \multicolumn{3}{|l|}{ Jenis kelamin } \\
\hline Laki-laki & 12 & 66,66 \\
\hline Perempuan & 6 & 33,34 \\
\hline \multicolumn{3}{|l|}{ Usia } \\
\hline Usia Muda < 40 Tahun & 2 & 11,11 \\
\hline Usia sedang 40-50 tahun & 9 & 50,00 \\
\hline Usia > 50 Tahun & 7 & 38,89 \\
\hline \multicolumn{3}{|l|}{ Lama kerja } \\
\hline$<5$ tahun & 3 & 16,66 \\
\hline $5-10$ tahun & 8 & 44,44 \\
\hline $10-15$ tahun & 1 & 5,55 \\
\hline$>20$ tahun & 6 & 33,33 \\
\hline \multicolumn{3}{|l|}{ Jumlah tempat praktik } \\
\hline 1 tempat praktik & 1 & 5,00 \\
\hline 2 tempat praktik & 9 & 50,00 \\
\hline 3 tempat praktik & 8 & 45,00 \\
\hline \multicolumn{3}{|l|}{$\begin{array}{l}\text { Gaji dan jasa pelayanan } \\
\text { yang diterima }\end{array}$} \\
\hline$<10$ juta rupiah & 1 & 5,55 \\
\hline $10-20$ juta rupiah & 4 & 22,22 \\
\hline $20-30$ juta rupiah & 3 & 16,66 \\
\hline $30-40$ juta rupiah & 5 & 27,77 \\
\hline $40-50$ juta rupiah & 3 & 16,66 \\
\hline$>50$ juta rupiah & 2 & 11,11 \\
\hline
\end{tabular}

Berdasarkan tabel 2 diketahui bahwa sebagian besar responden berjenis kelamin laki-laki $(66,66 \%)$ dan separuh responden berada pada kelompok usia 40 - 50 tahun (50\%). Hampir separuh responden telah bekerja selama 5 - 10 tahun (44,44\%), dan separuh responden memiliki 2 tempat praktik (50\%). Gaji dan jasa pelayanan yang diterima dokter dengan persentase tertinggi yaitu sebesar 30 40 juta rupiah $(27,77 \%)$.

Responden dengan kinerja baik dilakukan oleh DPJP dengan jumlah berkas rekam medis sedikit, namun ada tiga 
responden mempunyai berkas rekam medis banyak berkinerja baik yaitu dokter anak, penyakit dalam dan orthopedi. Kinerja kurang baik didominasi oleh DPJP dengan berkas rekam medis banyak. Pada penelitian ini ada contoh perbandingan dokumen klinis pada umumnya (kinerja kurang baik) dan dokumen klinis setelah diperbaiki (kinerja baik) yang ditampilkan pada Tabel3.

Tabel 3. Contoh perbandingan dokumen klinis pada umumnya dan setelah diperbaiki

\begin{tabular}{|c|c|}
\hline Dokumen Klinis Pada Umumnya & Dokumen Klinis Setelah Diperbaiki \\
\hline $\begin{array}{l}\text { Laki-laki } 40 \text { tahun keluhan nyeri perut, nyeri } \\
\text { pinggang, sulit BAK dan BAK adadarah, BAB cair. } \\
\text { T: 167/97. Pemeriksaan penunjang yang tertulis } \\
\text { hanya darah rutin (hasil dalam batas normal) } \\
\text { rekam jantung menunjukkan ada iskemik. } \\
\text { Pemeriksaan penunjang yang mendukung keluhan } \\
\text { lain (nyeri perut, nyeri pinggang, sulit BAK dan } \\
\text { BAK ada darah, BAB cair) tidak tertulis. }\end{array}$ & $\begin{array}{l}\text { Laki-laki } 40 \text { tahun keluhan nyeri perut, nyeri } \\
\text { pinggang, sulit BAK dan BAK ada darah, BAB } \\
\text { cair. T: 167/97. Pemeriksaan penunjang yang } \\
\text { tertulis darah rutin (hasil dalam batas normal) } \\
\text { rekam jantung menunjukkan ada iskemik. } \\
\text { Pemeriksaan penunjang yang mendukung } \\
\text { keluhan lain (nyeri perut, nyeri pinggang, sulit } \\
\text { BAK dan BAK ada darah, BAB cair) tertulis. } \\
\text { USG: Batu dan infeksi saluran kencing serta } \\
\text { batu empedu. Pemeriksaan feses rutin } \\
\text { ditemukanin infeksi bakteri. Hipertensi dan } \\
\text { hasil rekam jantung iskemik dikoreksi. }\end{array}$ \\
\hline Diagnosis : Abdominal pain & $\begin{array}{l}\text { Diagnosis : Iskemik Hipertensi Heart Disease, } \\
\text { Neprolithiasis, Kolethiasis, Diare karena infeksi } \\
\text { bakteri. }\end{array}$ \\
\hline ICD-10 R10.4 ICD-9 : 88,76 & $\begin{array}{l}\text { ICD-10 I 11.9, N20.0, K80.2, A09.9 ICD-9 } 88.76 \\
89.5290 .5990 .99\end{array}$ \\
\hline $\begin{array}{l}\text { Harga klaim INA-CBGs } \\
\text { Rp. } 1.968 .700,00\end{array}$ & $\begin{array}{l}\text { Harga klaim INA-CBGs } \\
\text { Rp. } 2.866 .300\end{array}$ \\
\hline
\end{tabular}


Tabel 4. Hasil uji bivariat

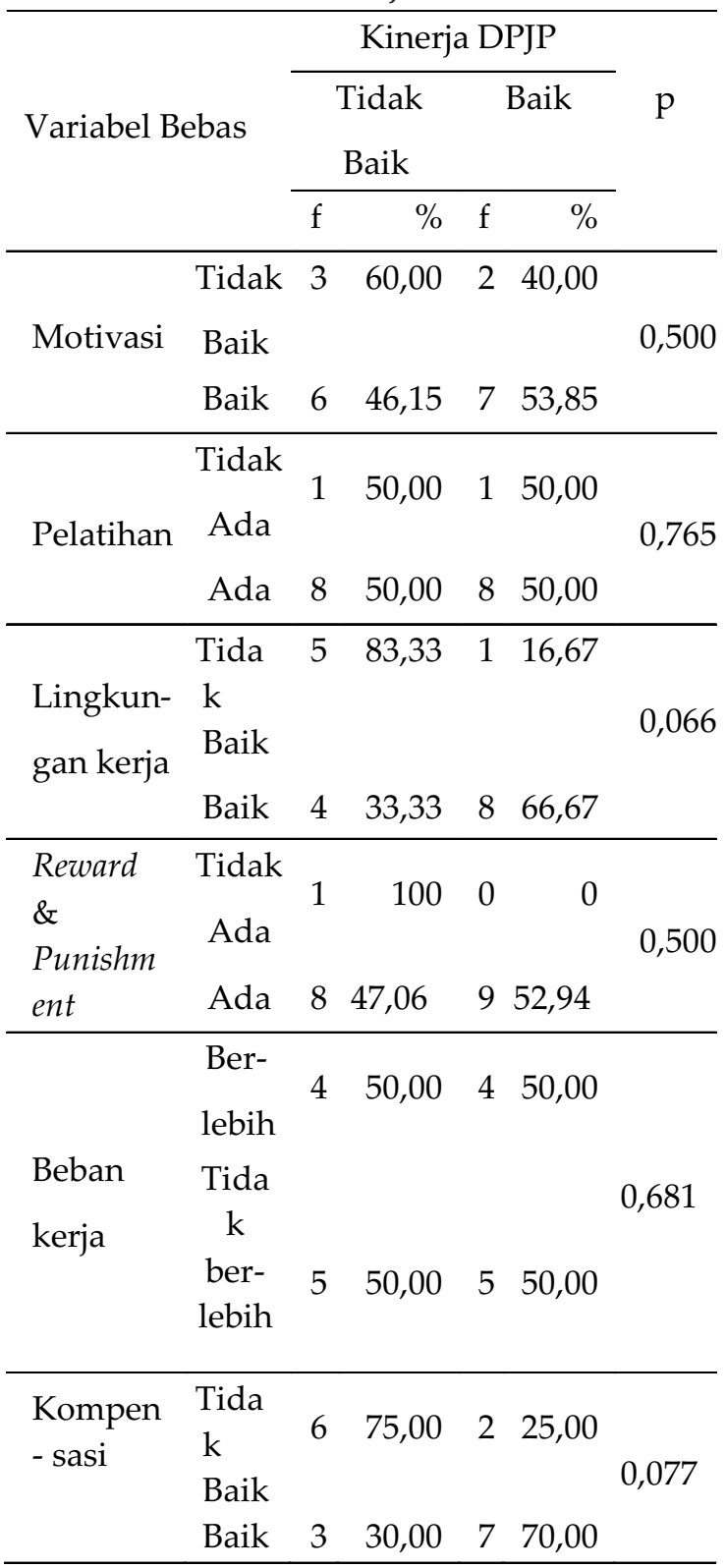

Berdasarkan tabel 4, pada variabel motivasi diketahui tiga responden memiliki motivasi tidak baik dan kinerja tidak baik $(60 \%)$, dan dua responden mempunyai motivasi tidak baik namun kinerjanya baik $(40 \%)$. Jumlah responden yang memiliki motivasi baik namun kinerjanya tidak baik sebanyak enam orang $(46,15 \%)$, dan tujuh responden dengan motivasi baik dan kinerja baik (53,85\%). Hasil p-value adalah 0,500 sehingga tidak ada hubungan antara motivasi kerja dengan kinerja DPJP. Hal ini sejalan dengan penelitian Yulianto pada tahun 2015 yang mengatakan jika semua dokter berpendapat bahwa bekerja adalah ibadah dan memanfaatkan ilmu yang diperoleh (Heru, 2015). Penelitian ini menunjukkan walaupun responden mempunyai motivasi baik, belum tentu mempunyai kinerja baik, demikian sebaliknya. Namun, hal ini tidak sejalan dengan penelitian Sudarmono pada tahun 2017 yang menyebutkan jika semakin tinggi motivasi dokter maka semakin tinggi juga kinerjanya, begitu pula sebaliknya semakin kurang motivasinya maka akan semakin rendah kinerja dokter tersebut (Sudarmono, 2017).

Walaupun penelitian ini tidak terdapat hubungan antara motivasi dan kinerja namun manajemen harus tetap memperhatikan motivasi terutama kepada dokter, karena dapat menjadi salah satu faktor meningkatkan kinerja di rumah sakit. Dengan motivasi kerja yang tinggi, dokter akan memiliki semangat tinggi dalam memberikan pelayanan yang terbaik bagi pasien dan diharapkan menjadi salah satu faktor meningkatkan kinerjanya (Heru, 2015). Penelitian kualitatif menunjukkanb a $\mathrm{h}$ w a walaupun mempunyai motivasi baik belum tentu DPJP mempunyai kinerja baik, demikian sebaliknya jika mempunyai motivasi kurang baik belum tentu mempunyai kinerja kurang baik dalam melaksanakan clinical document improvement.

Pada variabel pelatihan diketahui satu orang responden merasa tidak ada pelatihan dan kinerjanya tidak baik (50\%), dan satu orang responden merasa tidak ada pelatihan namun kinerjanya baik (50\%). Adapun jumlah responden yang merasa ada pelatihan namun kinerjanya tidak baik sebanyak delapan orang $(50 \%)$, dan delapan responden merasa ada pelatihan dan kinerja baik (50\%). Hasil $p$ value adalah 0,765 sehingga tidak ada hubungan antara pelatihan dan kinerja DPJP. Dari indepth interview menunjukkan jika di RSUD X Jawa Tengah belum pernah ada in house training tentang clinical document improvement, tetapi responden sangat setuju apabila manajemen mengadakan inhouse training. Sebagian besar responden dengan kinerja baik maupun kurang baik pernah 
disosialisasikan tentang pending klaim, hanya satu responden dengan kinerja baik merasa belum pernah disosialisasi tentang pending klaim, sehingga walaupun tidak ada pelatihan khusus, manajemen dan tim casemix sebaiknya memberikan sosialisasi tentang pending klaim terkait dokumen klinis agar lebih berkualitas, terutama bagian mayor yang lebih banyak pasiennya.

Penelitian kualitatif menunjukkan bahwa pelatihan yang dilakukan di RSUD X Jawa Tengah hanya dalam bentuk sosialisasi dari manajemen dan tim casemix dan tidak memengaruhi kinerja DPJP, karena walaupun ada sosialisasi, tetapi DPJP ada yang berkinerja dengan baik maupun kurang baik. Penelitian ini berbeda dengan penelitian Viva Maiga pada tahun 2012 yang menyatakan bahwa rendahnya ketepatan pengisian ICD-10 oleh dokter disebabkan lemahnya pengetahuan dan sikap dokter tentang arti penting ketepatan pengisian ICD-10, walaupun telah mengikuti sosialisasi dan pelatihan tentang ICD-10 dan INA-CBGs.

Dokter memiliki jumlah waktu yang terbatas dan lebih banyak memberikan waktu pelayanan kepada pasien, sehingga diperlukan pelatihan yang tidak membutuhkan waktu lama berupa in house training dan sosialisasi pentingnya ICD-10 untuk tenaga medis. Penting bagi manajemen untuk mengikutsertakan dokter dalam seminar JKN (Jaminan Kesehatan Nasional) dan mewajibkan tenaga medis ikut dalam sosialisasi JKN (Noor et al., 2014). Meskipun penelitian ini tidak berhubungan antara pelatihan dan kinerja, namun manajemen tetap harus memperhatikan faktor pelatihan untuk meningkatkan kinerja dokter. Pelatihan merupakan salah satu cara yang dilakukan perusahaan untuk mencapai tujuan agar output kinerjanya dapat berkualitas.

Pada variabel lingkungan kerja diketahui terdapat lima responden dengan lingkungan kerja tidak baik dan kinerjanya tidak baik $(83,33 \%)$, dan satu orang responden dengan lingkungan kerja tidak baik namun kinerjanya baik $(16,67 \%)$. Jumlah responden dengan lingkungan kerja baik namun kinerjanya tidak baik sebanyak empat orang $(33,33 \%)$, dan delapan responden dengan lingkungan kerja baik dan kinerja baik (66,67\%). Hasil p-value pada variabel ini adalah 0,066 sehingga tidak ada hubungan antara lingkungan kerja dengan kinerja dokter.

Lingkungan kerja dikatakan baik jika manusia dapat melaksanakan kegiatan secara optimal, sehat, aman dan nyaman sehingga lingkungan kerja yang kurang baik dapat menyebabkan tenaga dan waktu yang lebih banyak dan tidak mendukun tercapainya sistem kerja yang efisien (Sipatu, 2013). Berdasarkan hasil observasi lingkungan kerja, diketahui bahwa DPJP dalam menulis berkas rekam medis ada yang langsung menulis di dekat bed pasien, adapula yang menulis di nurse station yang kadang bersamaan dengan DPJP lain saat menulis berkas rekam medis ketika visite.

Hasil indepth interview menunjukkan secara umum responden mempunyai lingkungan kerja baik. Sebagian besar responden dengan kinerja baik maupun kurang baik menjawab tidak masalah jika desain bangsal rawat inap yang bercampur antar SMF karena tidak memengaruhi saat membuat dokumen klinik yang berkualitas. Hanya satu responden yang kinerjanya kurang baik dari DPJP bagian mayor (penyakit dalam) merasa kurang nyaman, karena harus keliling rumah sakit saat visite yang disebabkan karena hampir semua bangsal terdapat pasien dokter tersebut.

Penelitian kualitatif menunjukkan jika sebagian besar responden merasa lingkungan kerjanya tergolong nyaman, baik yang kinerjanya baik maupun kurang baik. Penelitian ini sejalan dengan penelitian Sipatu pada tahun 2013 yang menyatakan bahwa lingkungan kerja berpengaruh tidak signifikan terhadap kinerja. Meskipun lingkungan kerja berpengaruh tidak signifikan terhadap kinerja, namun penting untuk diperhatikan oleh manajemen karena jika seorang karyawan tidak 
berkinerja sesuai yang diharapkan, maka harus dilihat lingkungan kerjanya apakah mendukung atau tidak(Sipatu, 2013).

Pada variabel reward dan punishment terdapat satu orang responden yang merasa tidak ada reward dan punishment dan kinerjanya tidak baik $(100 \%)$, dan tidak ada responden yang merasa tidak ada reward dan punishment dan kinerjanya baik $(0 \%)$. Terdapat delapan responden yang merasa ada reward dan punishment namun kinerjanya tidak baik $(47,06 \%)$, dan 9 responden yang merasa ada reward dan punishment dan kinerjanya baik (52,4\%). Hasil $p$-value pada variabel ini adalah 0,500 sehingga tidak ada hubungan antara reward dan punishment dengan kinerja DPJP. Hasil indepth interview menunjukkan jika di RSUD X Jawa Tengah tidak memiliki kebijakan yang mengatur sistem reward dan punishment secara khusus. Reward berbentuk pujian pernah diberikan untuk DPJP yang tidak menyebabkan pending klaim karena kinerjanya baik sedangkan punishment berbentuk teguran dialami bagi empat responden yang mengalami pending klaim.

Penelitian kualitatif menunjukkan belum ditemukan kebijakan terkait reward dan punishment. Sistem reward hanya berbentuk pujian bagi DPJP dengan kinerja baik, dan punishment bagi DPJP dengan kinerja kurang baik dalam bentuk teguran. Sistem reward dan punishment di RSUD X Jawa Tengah ini sama dengan penerapannya di RSUD dr. Dradjat Prawiranegara Kabupaten Serang yaitu samasama belum terdapat kebijakannya dan berjalan dengan baik.

Penelitian ini berbeda dengan penelitian Dwi pada tahun 2013 yang menyatakan bahwa reward dan punishment menjadi salah satu kebijakan yang ditetapkan oleh Rumah Sakit Muhammadiyah Lamongan yang digunakan sebagai kerangka acuan menurunkan ketidaklengkapan pengisian DRM. Penting bagi manajemen untuk segera membuat kebijakan terkait konsekuensi kinerja dokter dalam membuat dokumen klinis yang berkualitas ((Mawarni and Wulandari, 2013);
(Setiadi et al., 2019)).

Pada variabel beban kerja terdapat empat responden dengan beban kerja berlebih dan kinerjanya tidak baik $(50 \%)$, dan empat responden dengan beban kerja berlebih namun kinerjanya baik (50\%), sedangkan lima orang responden dengan beban kerja tidak berlebih namun kinerjanya tidak baik $(50 \%)$, dan lima orang responden dengan beban kerja tidak berlebih dan kinerjanya baik (50\%). Hasil pvalue pada variabel ini adalah 0,681 sehingga tidak ada hubungan antara persepsi beban kerja dan kinerja DPJP. Berdasarkan hasil analisis kinerja, sebagian besar responden tidak merasa bahwa semakin banyak jumlah pasien maka nilai kinerjanya semakin kurang baik.

Penelitian kualitatif menunjukkan secara umum responden merasa tidak terbebani praktik sebagai DPJP dan praktik lebih dari satu tempat praktik. Responden dengan kinerja baik maupun kurang baik yang merasa sedikt terbebani terutama DPJP bagian mayor yaitu penyakit dalam dan anak. Satu diantaranya mengatakan sering kelelahan jika praktik lebih dari satu tempat dan menjawab konsulan $1 \times 24$ jam via telepon sehingga kadang mengurangi konsentrasi dalam bekerja.

Hal ini sejalan dengan penelitian Baharudin dkk pada tahun 2017 yang menyebutkan jika beban kerja dan jam kerja yang berlebihan memiliki pengaruh yang cukup signifikan terhadap kinerja dokter dan keselamatan pasien. Kelelahan merupakan salah satu faktor utama dari tenaga kesehatan yang dapat membahayakan pasien, karena memengaruhi konsentrasi dan kemampuan menyelesaikan tugas sehingga sering menjadi akar permasalahan dari kesalahan yang dilakukan dokter. Beberapa hal yang menyebabkan kelelahan pada dokter, antara lain kurang tidur dan kerja berlebihan (Baharuddin et al., 2017).

Penelitian Kanter dkk pada tahun 2016 menyatakan jika dokter penyakit dalam dan anak memiliki beban kerja yang tinggi (Sipatu, 2013). Penelitian ini sejalan dengan penelitian Ahid pada tahun 2012 yang menyatakan bahwa 
beban kerja tidak berhubungan dengan kinerja karena besar kecilnya beban kerja yang diterima karyawan tidak memengaruhi kinerja. Karyawan tetap bekerja dengan baik meskipun beban kerja yang diterima tinggi, selama masih termotivasi ketika bekerja. Beban kerja tetap perlu diperhatikan meskipun tidak berpengaruh terhadap kinerja, agar tidak terjadi beban kerja yang terlalu tinggi sehingga menimbulkan stres dan berdampak pada kinerja '(Kanter et al., 2016; Mudayana, 2013).

Pada variabel kompensasi diketahui terdapat enam responden dengan kompensasi tidak baik dan kinerjanya tidak baik (75\%), dua responden dengan kompensasi tidak baik namun kinerjanya baik (25\%), tiga responden dengan kompensasi baik namun kinerjanya tidak baik (30\%), dan tujuh responden dengan kompensasi baik dan kinerjanya baik (70\%). Hasil p-value pada variabel ini adalah 0,077 sehingga tidak ada hubungan antara kompensasi dan kinerja DPJP. Berdasarkan jawaban distribusi frekuensi disimpulkan jika sebagian besar sesuai dengan indikator kompensasi. Hanya satu indikator yang tidak sesuai yaitu kesesuaian jasa pelayanan dengan harapan.

Adanya expectancy model yang dikenal dengan The Porter-Lawler model of work motivation dimana kepuasan kerja diperoleh apabila hasil yang diterima sama dengan hasil yang diharapkan oleh karyawan (Revitasari, 2018). Hasil indepth interview menunjukkan secara umum responden dengan kinerja baik maupun kurang baik merasa ada ketidakadilan, ketidak transparanan dan ketidakpuasan terhadap jasa pelayanan yang diterima, hanya satu responden (dokter mitra) dengan kinerja baik yang merasa puas dengan penerimaan kompensasi dari RSUD X Jawa Tengah.

Hal ini berkebalikan dengan penelitian kuantitatif sebelumnya, dimana sebagian besar berpendapat mendapat kompensasi yang baik. Penelitian kuantitatif ini sejalan dengan penelitian Yulianto Heru pada tahun 2015 yang menyebutkan jika dokter spesialis merasa puas dengan balas jasa yang diterimanya, karena sudah ditetapkan standar perincian pembagian jasa pelayanan sesuai dengan aturan dan memberikan kepuasan kepada dokter.

Hal ini sesuai dengan teori yang dikemukakan oleh Steers et al yang mengatakan jika kepuasan kerja adalah sikap umum terhadap pekerjaan dengan melihat suatu perbedaan antara penghargaan yang seharusnya diterima dan bagaimana sikap perilaku seseorang terhadap pekerjaan (Heru, 2015). Penelitian kualitatif menunjukkan secara umum responden dengan kinerja baik maupun kurang baik merasa tidak ada keadilan, tidak transparan dan ketidak puasan terhadap jasa pelayanan yang diterima. Hanya satu responden (dokter mitra) dengan kinerja baik dari penelitian kualitatif yang merasa puas dengan penerimaan kompensasi dari RSUD X Jawa Tengah.

Penelitian ini berkebalikan dengan penelitian Sudarmono pada tahun 2017 yang menyatakan bahwa semakin tinggi kompensasi yang diberikan dokter maka semakin tinggi pula kinerjanya, demikian pula sebaliknya. Walaupun tidak ada hubungan antara kompensasi dan kinerja, tetapi kompensasi merupakan salah satu faktor penting yang harus diperhatikan manajemen agar dapat memotivasi karyawan, meningkatkan prestasi kerja dan meningkatkan kinerja mereka (Sudarmono, 2017).

\section{KESIMPULAN}

Tidak ada hubungan antara motivasi, pelatihan, lingkungan kerja, reward dan punishment, beban kerja, dan kompensasi dengan kinerja DPJP dalam melaksanakan clinical document improvementdi RSUD X Jawa Tengah. Secara umum untuk motivasi kerja, lingkungan kerja dan beban kerja masih baik, hanya kompensasi yang dianggap kurang baik karena tidak transparan dan tidak adil dalam pembagian jasa pelayanan. Belum ada pelatihan yang diselenggarakan di RSUD X Jawa Tengah serta belum ada kebijakan khusus yang mengatur sistem reward dan punishment. 


\section{DAFTAR PUSTAKA}

Baharuddin, M., Lefrandt, R., \& Santosa, F. (2017). Tinjauan Etik Regulasi Jam Kerja Dokter di Indonesia. Jurnal Etika Kedokteran Indonesia, 1(1), 25. https://doi.org/10.26880/jeki.v1i1.6

Dietz, Patty, Wagner, S. (2013). Clinical Documentation Improvement Measures,Models , and Multi -facilities. 22nd Annual Midas + User Symposium, 1-74. Ohio United Stated.

Heru, Y. (2015). Persepsi Dan Ekspektasi Dokter Terhadap Jasa Medis Di RS PKU Muham madiyah Nanggulan (Universitas Muhammadiyah Y o g y a k a r t a ; $\mathrm{V}$ o 1.4 ). https://doi.org/10.1145/3132847.3132886

Jamal, A., \& Grant, C. (2014). An Essential Guide to Clinical Documentation Improvement. Canada: Canadian Health Information Management Association.

Kanter, S., Posangi, J., \& Rattu, A. J. M. (2016). Analisis Kebutuhan Dan Kualifikasi Tenaga Dokter Dengan Metode Workload Indicators Staffing Need (WISN) Di Rumah Sakit Umum Daerah Noongan. Community Health, 1(1), 1-9.

Mawarni, D., \& Wulandari, R. D. (2013). Identifikasi Ketidaklengkapan Rekam Medis Pasien Rawat Inap Rumah Sakit Muham madiyah Lamongan. Identification of The Fulfilment of Medical Record Incompleteness in The Inpatient of Muhammadiyah Hospital Lamongan. Jurnal Administrasi Kesehatan, 1(2), 192-199.

Meutuah, L. D., \& Ishak, S. (2015). Analisis Kepuasan Dokter Spesialis Terhadap Program Jaminan Kesehatan Nasional (JKN) Di Rumah Sakit Umum Daerah Dr. Zainoel Abidin Tahun 2014. Jurnal Kedokteran Syiah Kuala, 15(1), 7-19.

Mudayana, A. A. (2013). Hubungan Beban Kerja dengan Kinerja Karyawan di Rumah Sakit Nur Hidayah Bantul. Jurnal Kesehatan Masyarakat (Journal of Public Health), 6(1), 35-40. https://doi.org/10.12928/kesmas.v6i1.106 $\underline{5}$

Noor, V. M. M., Ansyori, A., \& Hariyanto, T. (2014). Peran Pengetahuan dan Sikap Dokter dalam Ketepatan Koding Diagnosis berdasar ICD 10. Jurnal Kedokteran Brawijaya, 28(1), 65-67. https://doi.org/10.21776/ub.jkb.2014.028. $\underline{01.25}$

Reid, A. (2016). Improving Clinical Documentation Performance in Healthcare : Use of Project Quality Management. ProQuest LLC, 1-64.

Revitasari, A. (2018). Identifikasi Ketidaklengkapan Pengisian Dokumen Rekam Medis Rawat Jalan Berdasarkan Teori Motivasi Ekspektansi. Jurnal Administrasi Kesehatan Indonesia, 4(2), 86. https://doi.org/10.20473/jaki.v4i2.2016.86 $\underline{-96}$

Reyes, C., Greenbaum, A., Porto, C., \& Russell, J. C. (2017). Implementation of a Clinical Documentation Improvement Curriculum Improves Quality Metrics and Hospital Charges in an Academic Surgery Department. Journal of the American College of Surgeons, 224(3), $\begin{array}{llllllll}3 & 0 & 1 & - & 3 & 0 & 9\end{array}$. https://doi.org/10.1016/j.jamcollsurg.201 $\underline{6.11 .010}$

Setiadi, R., Rahayu, S., \& Sangadji, I. (2019). Pengelolaan Kehadiran Kinerja Dokter Dalam Upaya Meningkatkan Kualitas Pelayanan Poliklinik di RSUD dr. Dradjat Prawiranegara Kabupaten Serang. 3(2), 111-118.

Setyorini, T. (2018). Pengembangan Model Instrumen Penilaian Kinerja Dokter Spesialis Obsgyn Melalui Analisis Kinerja di Rumah Sehat Ibu Dan Anak Budi Kemuliaan. Jurnal Administrasi Rumah Sakit Indonesia, 2(2), 162-171. https://doi.org/10.7454/ARSI.V2I2.2198

Sipatu, L. (2013). Pengaruh Motivasi, Lingkungan Kerja Dan Stres Kerja Terhadap Kinerja Perawat Di Ruang Rawat Inap RSUD Undata Palu. Katalogis, 
1(1), 147-158.

Sudarmono. (2017). Hubungan Kompensasi, Motivasi dan Kepuasan Kerja dengan Kinerja Dokter. 5(April), 43-46.

Syahidin, R. (2018). Pengaruh Kompensasi Dan Motivasi Dokter Terhadap Kepuasan
Kerja Dokter Di Rumah Sakit Tipe C Di Wilayah Bandung Raya. Journal Manajemen Dan Bisnis (Almana), 2(9), $\begin{array}{llll}1 & - & 1 & 9\end{array}$ https://doi.org/10.1017/CBO97811074153 $\underline{24.004}$ 